\title{
Characterization of Al/Ti Nano Multilayer as a Jointing Material at the Interface between $\mathrm{Cu}$ and $\mathrm{Al}_{2} \mathrm{O}_{3}$
}

\author{
Jianglong. Yi ${ }^{1, *}$, Yupeng Zhang ${ }^{1}$, Xinxin Wang ${ }^{1}$, Chunlin Dong ${ }^{1}$ and Haichun $\mathrm{Hu}^{2}$ \\ ${ }^{1}$ Guangdong Welding Institute (China-Ukraine E. O. Paton Institute of Welding) Guangdong Provincial Key Laboratory of Advanced \\ Welding Technology, Guangdong academy of Sciences, Guangzhou, 510651, China \\ ${ }^{2}$ Beijing Pins Medical Co., Ltd., Beijing, 102299, China
}

\begin{abstract}
In this paper, a series of $\mathrm{Al} / \mathrm{Ti}$ multilayers with different modulation periods were used in copper and $\mathrm{Al}_{2} \mathrm{O}_{3}$ ceramic diffusion bonding. The reactive multilayer was deposited by DC magnetron sputtering, and the diffusion bonding experiments were performed at $900^{\circ} \mathrm{C}$ for $10 \mathrm{~min}$ with a pressure of $5 \mathrm{MPa}$. The interfacial joints were inspected by scanning electron microscopy (SEM), energy dispersive x-ray spectroscopy (EDS), X-ray diffraction and tensile shear tests. As a result, no significant metallurgical defect was observed in the microstructures of the joints. The formation of several intermetallic compounds at the interface, such as $\mathrm{Cu} / \mathrm{Ti}$ eutectic and $\mathrm{Al}_{2} \mathrm{O}_{3-\mathrm{X}} \cdot \mathrm{TiO}$ compound, has further confirmed the success of $\mathrm{Cu}-\mathrm{Al}_{2} \mathrm{O}_{3}$ bonding as compared to the $\mathrm{Al} / \mathrm{Ni}$ nano-multilayers, which use $\mathrm{Al} / \mathrm{Ti}$ nano-foils as interlayer for diffusion bonding to bring more benefit to the quality of cermet joint. [doi:10.2320/matertrans.M2016126]
\end{abstract}

(Received April 4, 2016; Accepted June 29, 2016; Published July 29, 2016)

Keywords: aluminium-titanium, Nano-multilayers, diffusion bonding, interface

\section{Introduction}

Alumina is a well-known oxide ceramic material, which is widely used in vacuum tubes, insulation layers and so on ${ }^{1)}$. Since it is necessary to bond alumina and metal materials in many cases, then there is a demand for a robust ceramic-metal joint material. During the last decade, researchers have implemented a wide range of methods in ceramic-metal joining. However, due to different physical/chemical properties in the physical and chemical structures of ceramics and metals, only a few methods appear to be feasible for application ${ }^{2}$. As a novel method, the application of nano multilayer seems to be one of the most suitable methods for diffusion bonding. This joining technique has many excellent advantages over conventional joining technologies (soldering or brazing). First, the nano-multilayered foils can release external heat by self-propagating exothermic reactions, allowing the temperature sensitive materials to join at a low temperature ${ }^{3)}$. Second, thanks to the mutual diffusing reaction occurring at the interface of the bonding components, this process can yield a strong bonding layer ${ }^{4}$.

Titanium-intermetallics are promising candidates for alumina-metal joining, especially in mechanical applications. The titanium aluminide phases are generated during the solid-state reaction of $\mathrm{Al} / \mathrm{Ti}$ multilayers at the temperature of $600^{\circ} \mathrm{C}^{5}$. In the meantime, the $\mathrm{Al} / \mathrm{Ti}$ nano-foils are widely applied in diffusion bonding as a reactive bonding material, which can release intense heat after an ignited self-propagation reaction. Therefore, it has the potential of being used in ceramic-metal joining. In this work, a series of Al-Ti reactive multilayers with different modulation periods were used as the interlayer for the diffusion bonding of copper and $\mathrm{Al}_{2} \mathrm{O}_{3}$ ceramic.

*Corresponding author, E-mail: scutyj1@163.com

\section{Experimental}

To prepare the $\mathrm{Al} / \mathrm{Ti}$ nano-multilayers, titanium (purity: 99.99\%) and aluminum (purity: $99.95 \%$ ) were used as targets. The $\mathrm{Al} / \mathrm{Ti}$ films were fabricated on copper base by high vacuum magnetron sputtering method (type: JGP-560b, ShenYang scientific instruments company, The Chinese Academy of Sciences). Parameters of different modulation periods for Al-Ti nanofoils were listed in Table 1.

The prepared nano-foils were cut into small pieces for ceramic-metal joining. The three bonding parts-pure alumina piece $(10 \mathrm{~mm} \times 15 \mathrm{~mm} \times 10 \mathrm{~mm}$, SHENZHEN HAIDE Co., LTD. Shenzhen, China), copper plate $(\Phi 30 \times 10 \mathrm{~mm}$, TUI-Oxygen free copper, SUZHOU JINJIAYE Co., LTD. Suzhou, China) and $\mathrm{Al} / \mathrm{Ti}$ foils were assembled as shown in Fig. 1. Before being assembled, each of them was cleaned by sonication in distilled water, acetone, and isopropyl alcohol for 10 min respectively. The copper and $\mathrm{Al}_{2} \mathrm{O}_{3}$ blocks bonded in a vacuum furnace with Al-Ti nano-multilayer of different bilayer thickness as the interlayer were listed in Table 1. The specimens were taken to the bonding chamber of the vacuum diffusion welding furnace system (CENTORR VACUUM INDUSTRIES INC.) The temperature was raised to $900^{\circ} \mathrm{C}$ at a rate of $10^{\circ} \mathrm{C} / \mathrm{min}$ and then held at this value for $15 \mathrm{~min}$ under the pressure of $5 \mathrm{MPa}$. Finally, the bonded samples were gradually cooled to room temperature at a rate of $5^{\circ} \mathrm{C} / \mathrm{min}$.

Table 1 Parameters of five Al-Ti nano-multilayer foils.

\begin{tabular}{cccccc}
\hline Specimen No. & $d_{A l}, \mathrm{~nm}$ & $d_{T i}, \mathrm{~nm}$ & $\eta$ & $\lambda, \mathrm{nm}$ & $d, \mu \mathrm{m}$ \\
\hline $1 \#$ & 900 & 1030 & $1: 1$ & 1930 & 44 \\
$2 \#$ & 650 & 230 & $3: 1$ & 880 & 38 \\
$3 \#$ & 380 & 135 & $3: 1$ & 515 & 41 \\
$4 \#$ & 225 & 80 & $3: 1$ & 305 & 31 \\
$5 \#$ & 100 & 35 & $3: 1$ & 135 & 20 \\
\hline
\end{tabular}

$d_{A l}$-hickness of Al layer, $d_{T i}$-thickness of Ti layer, $\eta$-atomic ratio of Al to $\mathrm{Ti}, \lambda$-modulation period, $d$-total thickness of the foil. 


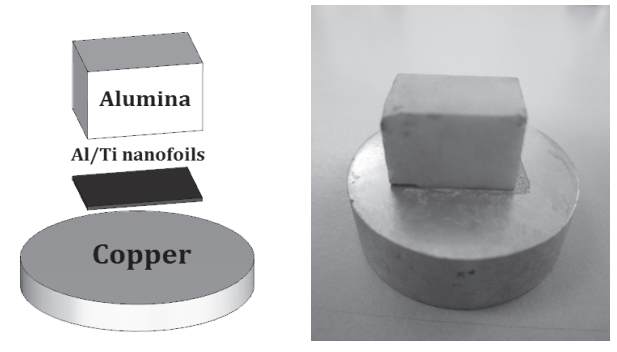

Fig. 1 Schematic illustration of assembling the $\mathrm{Cu} / \mathrm{Al}_{2} \mathrm{O}_{3}$ joint.

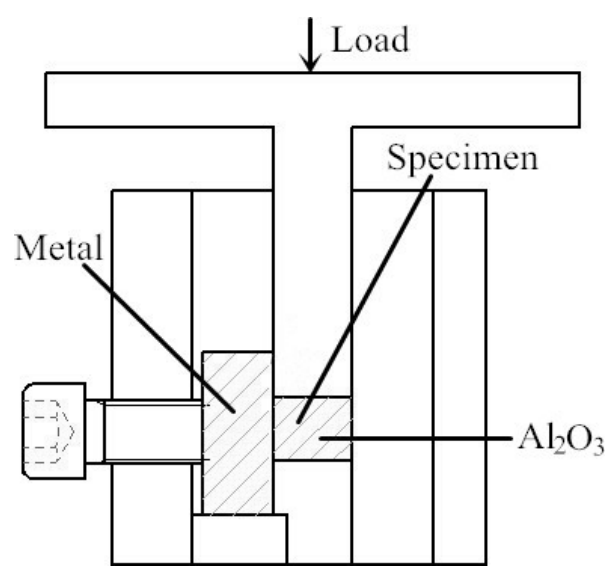

Fig. 2 Chart of the joints shear strength testing method.

The shear strength of the as-bonded ceramic-metal joint was measured by the method according to Zhang et al. ${ }^{6}$, as shown in Fig. 2. Some of the bonded joints were cut and measured by SEM to analyze the microstructures and compositions of the welding interface. Meanwhile, X-ray diffraction methods (XRPD, D/MAX- RC) were adopted to identify the products of interfacial reaction by comparing the joints interface with the multilayered foils.

\section{Results and Discussion}

\subsection{Microstructure analysis on different joints}

In Zhang's work, ${ }^{6)}$ he developed a formula to calculate the reaction heat of Al-Ni nano multilayers with equal atomic ratio in the self-propagating process based on the work of Kim et $a l .{ }^{7)}$ Due to the similarity of two reactions, this formula (1) can be used to estimate the reaction heat of Al-Ti nano-multilayers self-propagation reaction.

$$
\Delta H=\Delta H_{0}\left(1-\frac{2 \omega+t}{\lambda}\right)
$$

$\Delta \mathrm{H}_{0}$ is the maximum amount of heat that can be released from the reaction, in which $\lambda$ is the bilayer period, $\omega$ represents the thickness of the intermixed layer and $t$ is the influence factor of excessive $\mathrm{Ti}$ or $\mathrm{Al}$. Based on consideration of the formula and the thermal analysis of five Al-Ti nano-foils ${ }^{8)}$, we know that the bilayer thickness and period of different foils will affect the heat released from diffusion bonding, and will directly determine the interfacial phases of the ceramic-metal joint. Hence, we chose those five different nano AlTi foils for the diffusion bonding of copper and $\mathrm{Al}_{2} \mathrm{O}_{3}$ ceram-
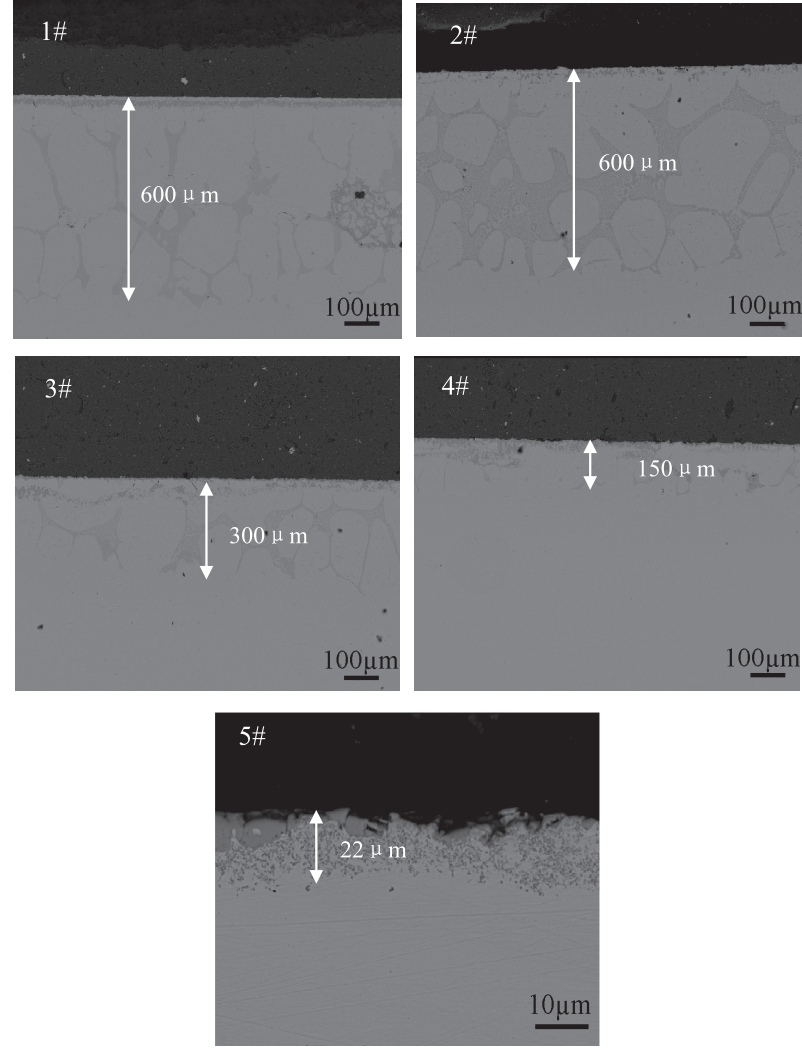

Fig. 3 the microstructure of the $\mathrm{Cu} / \mathrm{Al}_{2} \mathrm{O}_{3}$ joints with different $\mathrm{Al} / \mathrm{Ti}$ nano-foils.

ic.

Figure 3 revealed the microstructure of different $\mathrm{Cu} / \mathrm{Al}_{2} \mathrm{O}_{3}$ joints with different $\mathrm{Al} / \mathrm{Ti}$ nano-foils. It indicated that both copper and alumina sides joined during the self-propagation process of Al-Ti nano-multilayer foils, and there was no crack or pore that could be observed in the fusion zone microstructure of the joint. Meanwhile, the four interface microstructures (Specimen No.1 to No.4) contained many framework structure grains. Both evidences have verified that the successful diffusion bonding of $\mathrm{Cu} / \mathrm{Al}_{2} \mathrm{O}_{3}$ can only be realized by using Al-Ti nano-multilayer foils as the interlayer.

The five Al-Ti nano-multilayer foils can be grouped into two types: one is type $\mathrm{A}$, with an atomic ratio between $\mathrm{Al}$ and Ti of $1: 1$, the other one is type $\mathrm{B}$, with an atomic ratio between $\mathrm{Al}$ and $\mathrm{Ti}$ of $3: 1$. As the modulation period of the type B Al-Ti nano-foils increased from $305 \mathrm{~nm}$ to $880 \mathrm{~nm}$, the thickness of reactive interface raises from $150 \mu \mathrm{m}$ to $600 \mu \mathrm{m}$. For type A, the thickness did not increase with the modulation period even though the period reached $1930 \mathrm{~nm}$. According to the microstructure observation mentioned above, it was found that the atomic ratio between $\mathrm{Al}$ and $\mathrm{Ti}$ could not directly influence microstructure of the fusion zone. In contrast, the thickness of diffusion reaction zone significantly approached $22 \mu \mathrm{m}$ while the modulation period decreased to $135 \mathrm{~nm}$. Moreover, no more fishbone-like eutectic phase appeared in the microstructure of the reaction interface. This suggests that the modulation period of Al-Ti nano-foils is the key factor for the diffusion bonding of copper and $\mathrm{Al}_{2} \mathrm{O}_{3}$ ceramic. Thus, by controlling the modulation period of multilayer, the microstructure of diffusion reaction zone can be 

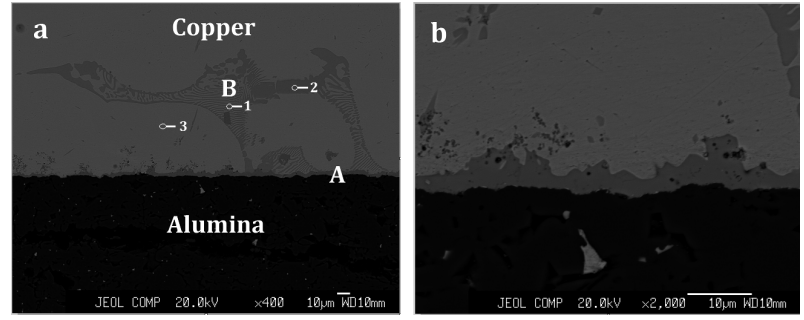

Fig. 4 Micrographs by SEM: (a) Micrograph of the $\mathrm{Al}_{2} \mathrm{O}_{3} / \mathrm{Cu}$ interface and element analysis by EDS ; (b) more detail microstructure about the fusion zone A.

Table 2 EDS analysis result in the Marked Positions Shown in Fig. 3(a) (mass\%)

\begin{tabular}{cccc}
\hline Marked Positions & $\mathrm{Al}$ & $\mathrm{Ti}$ & $\mathrm{Cu}$ \\
\hline 1 & 6.69 & 43.37 & 49.94 \\
2 & 8.30 & 20.02 & 71.68 \\
3 & 3.84 & 0.59 & 95.57 \\
\hline
\end{tabular}

controlled.

\subsection{Joining zone and phase analysis of different joints}

In order to learn more detail about the ceramic-metal joint, we chose the fourth cermet joint (by using foil 4 as the interlayer) as example. Figure 4 revealed the cross section micromorphology of the cermet-joining zone. It could be seen from Fig. 4(a) that both copper and alumina sides joined in the self-propagation process of Al-Ti multilayered foils at the temperature of $900^{\circ} \mathrm{C}$. There were no obvious defects, such as micro-cracks and Kirkendall pores, which could be observed in the reaction area. The layer structure of Al-Ti multilayers was changed to a very thick fusion interface during the diffusion bonding procedure. An interface with two distinct zones could be seen as identified in Fig. 4(a): zone A (close to alumina material) exhibited small density grains belonging to the copper side; zone B had fish skeleton-like framework structure grains. More detail microstructure of the ceramic-metal joint could be found in Fig. 4(b), which has confirmed the successful diffusion bonding process.

The interface was studied by EDS analysis to investigate the interfacial phases. It was found that the keleton-like framework structure grains of zone B (in Table 2) was $\mathrm{Cu}-\mathrm{Ti}$ intermetallic phase, which was formed by the element diffusion of $\mathrm{Al} / \mathrm{Ti}$ nano-foils.

The EDS line-analyses on the cross-sections of the joint were presented in Fig. 5. For the copper base material, $\mathrm{Cu}$ and Ti elements were detected, which further proved the formation of $\mathrm{Cu}$-Ti intermetallic phase. Not only $\mathrm{Al}$ and $\mathrm{Ti}$ were detected at the interfacial zone, but also $\mathrm{O}$ element was identified near the $\mathrm{Al}_{2} \mathrm{O}_{3}$ ceramic side. $\mathrm{Cu}$ was also the dominant element on copper side of the fusion zone. This indicates that the diffusing reaction occurs at both sides of joints. It is well known that diffusion of Ti element is the key factor for the formation of the ceramic interface ${ }^{9)}$. As a reactive element, $\mathrm{Ti}$ reduced alumina to $\mathrm{Al}$ and $[\mathrm{O}]$ according to the following reaction $^{10)}$ :

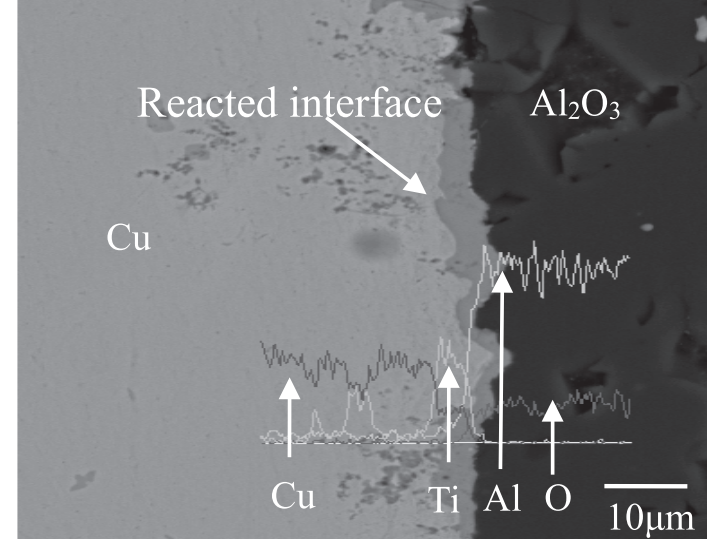

Fig. 5 EDS line-analyses over the cross-sections of joint.

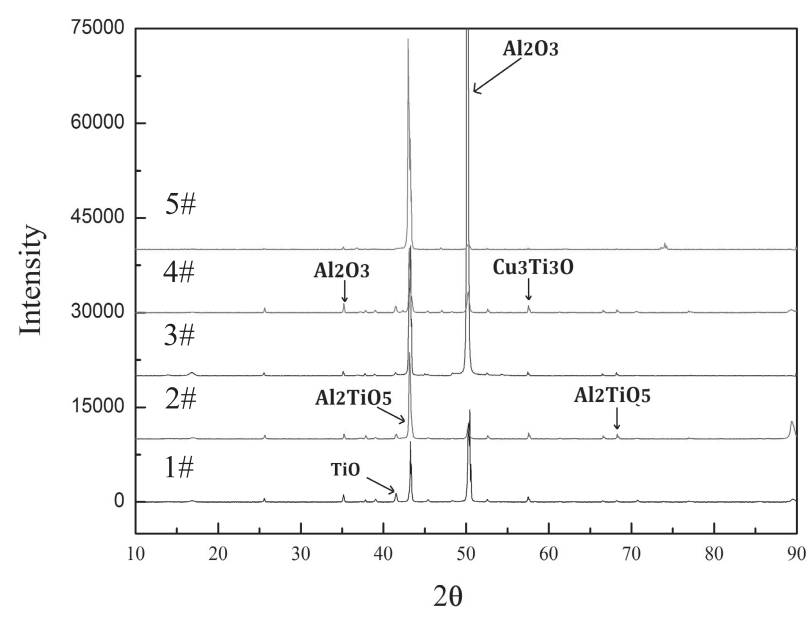

Fig. 6 the XRD patterns of the $\mathrm{Cu} / \mathrm{Al}_{2} \mathrm{O}_{3}$ joints with different $\mathrm{Al} / \mathrm{Ti}$ nano-foils.

$$
\mathrm{Ti}+\mathrm{Al}_{2} \mathrm{O}_{3} \rightarrow \mathrm{Ti}[\mathrm{O}]_{3 \mathrm{x}}+2 \mathrm{xAl}
$$

In the present case, the active $\mathrm{Ti}[\mathrm{O}]_{3 \mathrm{x}}$ will further react with $\mathrm{Al}_{2} \mathrm{O}_{3}$ ultimately to form the composite of $\mathrm{Al}_{2} \mathrm{O}_{3-\mathrm{X}}$. $\mathrm{TiO}(\mathrm{X}<1)$.

Figure 6 showed the phase composition of the reaction interface, in which the major peaks represented $\mathrm{Al}_{2} \mathrm{O}_{3}$ substrate. Due to strong peaks of alumina and less concentration of reaction products, the intensity of other peaks was very low. It included $\mathrm{Al}_{2} \mathrm{TiO}_{5}, \mathrm{Cu}_{3} \mathrm{Ti}_{3} \mathrm{O}$, and $\mathrm{TiO}$ phases, which were consistent with the former EDS results and other published research work conducted by experts, such as Kar et al. who have reported that $\mathrm{Al}_{2} \mathrm{TiO}_{5}$ and $\mathrm{Cu}_{3} \mathrm{Ti}_{3} \mathrm{O}$ phases have been found at the $\mathrm{Al}_{2} \mathrm{O}_{3}$ interface ${ }^{11)}$. Kar et al. also found the presence of $\mathrm{TiO}$ and $\mathrm{Cu}_{3} \mathrm{Ti}_{3} \mathrm{O}$ phases at the $\mathrm{Al}_{2} \mathrm{O}_{3}$ interface ${ }^{12)}$.

\subsection{Joint shear strength}

The shear strength of the $\mathrm{Cu} / \mathrm{Al}_{2} \mathrm{O}_{3}$ joints was evaluated at room temperature, as shown in Fig. 7. When the joint strength of the five samples was tested, all fractures occurred in the alumina section matrix. This indicates that the phases present in the alumina interface are quite brittle than those belonging to the copper interface. Although based on the work of Ksiazek et al., the joint strength increased as the joint thickness 


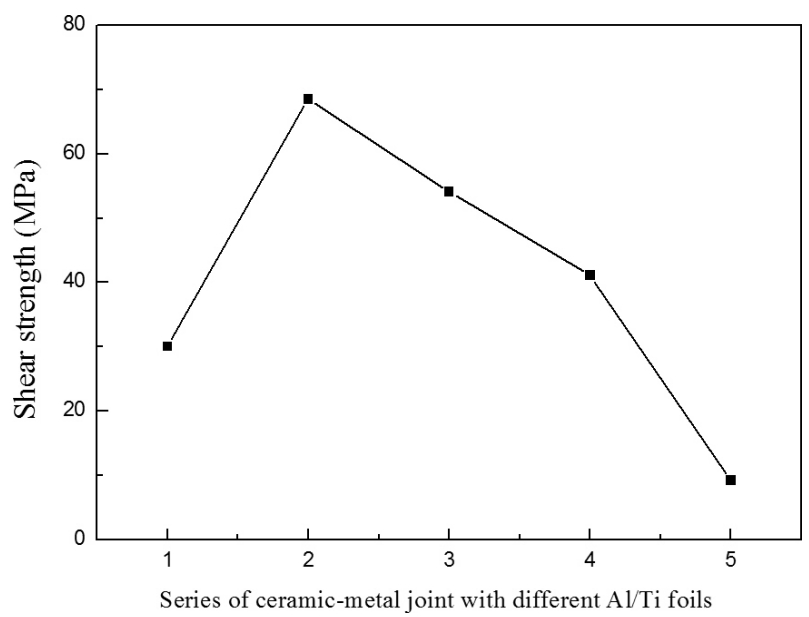

Fig. 7 Joint shear strength of $\mathrm{Cu} / \mathrm{Al}_{2} \mathrm{O}_{3}$ joints.

reduced $^{13)}$. Palit et al. have found that the joint shear strength increases with the thickness of interface ${ }^{14)}$. From this study, for the type B nano-multilayer foils (the atomic ratio between $\mathrm{Al}$ and $\mathrm{Ti}$ is 3:1), when the thickness of react interface rose from $22 \mu \mathrm{m}$ to $600 \mu \mathrm{m}$, the shear strength significantly increased from 9.25 MPa to 68.5 MPa. For type A nano-foils (the atomic ratio between $\mathrm{Al}$ and $\mathrm{Ti}$ is $1: 1$ ), the shear strength sharply decreased to $30.3 \mathrm{MPa}$, while the thickness of react interface still retained at $600 \mu \mathrm{m}$.

Owing to the high dissolution and chemical reactions ability of the Al-Ti nano-foils, except specimen No. 5, the other $\mathrm{Cu} / \mathrm{Al}_{2} \mathrm{O}_{3}$ joints yielded higher strength than the cermet joint obtained in our former study ${ }^{15}$ ). In the past, we have used $\mathrm{Al}-\mathrm{Ni}$ nano-foil and CuSnTi solder as the interlayer to join copper and alumina, and the shearing strengths of cermet joint ranged from $19 \mathrm{MPa}$ to $26 \mathrm{MPa}$. It can be inferred from the above analysis that the ceramic-metal joint strength is mostly determined by the microstructure and thickness of interface.

\section{Conclusions}

$\mathrm{Al}_{2} \mathrm{O}_{3}$ ceramic and copper joint have been successfully performed by diffusion bonding with $\mathrm{Al} / \mathrm{Ti}$ nano-foils as interlayer. Comparing it with our former study ${ }^{15)}$, we just used nano-foils as interlayer without any other solder in this work. Application of $\mathrm{Al} / \mathrm{Ti}$ nano-foils has brought more benefit to the quality of cermet joint than the $\mathrm{Al} / \mathrm{Ni}$ nanolayers.

There were no significant metallurgical defects observed in the microstructure of all the five ceramic-metal joints. The best atomic ratio and modulation period formed a proper microstructure and thickness of alumina/copper joints as 1:1 and $880 \mathrm{~nm}$ respectively. Meanwhile, the shear strength of the cermet joint was $68.5 \mathrm{MPa}$.

Systematic analysis on the fusion reaction zone of ceramic-metal joint reveals that the atomic ratio and modulation period directly influence the microstructure and thickness of interface. The quality of interface will finally determine the reliability of joints. Thus, by controlling the fabrication process of the multilayer, we can obtain an ideal cermet joint. Further research will focus on the development of using nano-foil for the diffusion bonding of other advanced ceramics.

\section{Acknowledgement}

The authors thanks for the supports by the project of the National Natural Science Foundation of China (Grant No. 51405092), the program of the Pearl River Young Talents of Science and Technology in Guangzhou (No.2013J2200033), the project of Guang-dong Provincial Key Laboratory (No.2012A061400011).

\section{REFERENCES}

1) C.G. Zhang, G.J. Qiao and Z.H. Jin: J. Eur. Cera. Soc. 22 (2002) 21812186.

2) I. Foroutan, R.S. Mamoory and N. Hosseinabadi: Ceram. Int. 36 (2010) 741-747.

3) L. Edward. Dreizin: Prog. Energ Combust. 35 (2009) 141-167.

4) T.S. Lin, L.J. Gao, P. He, X.L. Gu and Y.D. Huang: Mater. Rev. 21 (2011) 60-66 (in chinese).

5) D. Peruško, S. Petrović, J. Kovač, Z. Stojanović, M. Panjan, M. Obradović and M. Milosavljević: J. Mater. Sci. 47 (2012) 4488-4495.

6) Y.P. Zhang, Y.Q. Yang, J.L. Yi and H.C. Hu: Mater. Trans. 54 (2013) 931-933.

7) H.Y. Kim, D.S. Chung and S.H. Hong: Scr. Mater. 54 (2006) 17151719.

8) H.C. Hu, Y. P. Zhang, X.K. Zhao, Y.Y. Yi, J.L. Yi and M.J. Dai: Hot Working Technology (in chinese), 43 (2014) 213-219.

9) A. Kar and A.K. Ray: Mater. Lett. 61 (2007) 2982-2985.

10) A.M. Kliauga, D. Travessa and M. Ferrante: Mater. Charact. 46 (2001) 65-74.

11) A. Kar and M. Ghosh, A.K. Ray and A.K. Ray,: Mater. Sci. Eng. A 498 (2008) 283-288.

12) A. Kar, S. Mandal, K. Venkateswarlu and A.K. Ray: Mater. Charact. 58 (2007) 555-562.

13) M. Ksiazek, N. Sobczak, B. Mikulowski, W. Radziwill and I. Surowiak: Mater. Sci. Eng. A 324 (2002) 162-167.

14) D. Palit and A.M. Meier: J. Mater. Sci. 41 (2006) 7197-7209.

15) J.L. Yi, Y.P. Zhang, H.C. Hu, X.X. Wang, H.X. Chen and M.J. Dai: Rare Met. Mater. Eng. 43 (2014) 2593-2596. 